Journal of

Information Systems Engineering and Business Intelligence

Vol. 4, No. 2, October 2018

Available online at: http://e-journal.unair.ac.id/index.php/JISEBI

\title{
Corrigendum: Sentiment Analysis in the Sales Review of Indonesian Marketplace by Utilizing Support Vector Machine
}

\author{
Anang Anggono Lutfi ${ }^{1)}$, Adhistya Erna Permanasari' ${ }^{2)}$, Silmi Fauziati ${ }^{3)}$ \\ ${ }^{12) 3)}$ Department of Electrical Engineering and Information Technology,Universitas Gadjah Mada \\ Jl. Grafika 2, Yogyakarta - 55281, Indonesia \\ 1)anang.anggono.lutfi@mail.ugm.ac.id \\ 2)adhistya@ugm.ac.id \\ 3)silmi@ugm.ac.id
}

Journal of Information Systems Engineering and Business Intelligence, 2018, 4 (1), 57-64

Published online 28 April 2018; Corrected after print 28 October 2018

In the version of this article initially published, there were some errors in Section III, Methods and Section VI, Conclusions. In Preprocessing of Methods, there is a sentence "The informal words may be in the form of slang words or abbreviations that are often used in daily life like $\mathrm{cp}$ at (from "cepat" or fast), blum (from "belum" or not yet), and gak (from "tidak" or no).". The correct sentence is "The informal words may be in the form of slang words or abbreviations that are often used in daily life like cpat (from "cepat" or fast), blum (from "belum" or not yet), and gak (from "tidak" or no).". In Text Classification of Methods, there is a sentence "Where $\mathrm{P}(\mathrm{B} \mid \mathrm{A})$ is the probability of $B$ appearance when $A$ is known? The value $P(A \mid B)$ is the probability of an appearance if $B$ is known. $P(A)$ is the probability of an appearance, while $\mathrm{P}(\mathrm{B})$ is the probability of $\mathrm{B}$ appearance.". The correct sentence is "Where $\mathrm{P}(\mathrm{B} \mid \mathrm{A})$ is the probability of the appearance of $\mathrm{B}$ when $\mathrm{A}$ is known. The value of $\mathrm{P}(\mathrm{A} \mid \mathrm{B})$ is the probability of the appearance of $\mathrm{A}$ if $\mathrm{B}$ is known. $\mathrm{P}(\mathrm{A})$ is the probability of the appearance of $\mathrm{A}$, while $\mathrm{P}(\mathrm{B})$ is the probability of the appearance of B.". In Conclusions, a sentence "The accuracy reaches $93.42 \%$; using 25\% features with highest TFIDF" should be changed to "The accuracy reaches 93.65\%; using 25\% features with highest TF-IDF" based on the results in Fig.3. These errors have been corrected in the PDF versions of the article. 